\title{
Overview of the Pathology of Three Widely Used Animal Models of Acute Lung Injury
}

\author{
H.M. Wang ${ }^{a, b} \quad$ M. Bodenstein ${ }^{a} \quad K$. Markstaller $^{a}$ \\ a Department of Anesthesiology, Johannes Gutenberg University, Mainz, Germany; ${ }^{b}$ National Beijing Center for \\ Drug Safety Evaluation and Research, Beijing Institute of Pharmacology and Toxicology, Beijing, PR China
}

\section{Key Words}

Animal model - Acute lung injury · Pathology · Oleic acid · Lavage $\cdot$ Endotoxin/lipopolysaccharide

\begin{abstract}
Acute lung injury (ALI) and acute respiratory distress syndrome (ARDS) are syndromes of acute diffuse damage to the pulmonary parenchyma by a variety of local or systemic insults. Increased alveolar capillary membrane permeability was recognized as the common end organ injury and a central feature in all forms of ALI/ARDS. Although great strides have been made in understanding the pathogenesis of ALI/ ARDS and in intensive care medicine, the treatment approach to ARDS is still relying on ventilatory and cardiovascular support based on the recognition of the clinical picture. In the course of evaluating novel treatment approaches to ARDS, 3 models of ALI induced in different species, i.e. the surfactant washout lavage model, the oleic acid intravenous injection model and the endotoxin injection model, were widely used. This review gives an overview of the pathological characteristics of these models from studies in pigs, dogs or sheep. We believe that a good morphological description of these models, both spatially and temporally, will help us gain a better understanding of the real pathophysiological picture and apply these models more accurately and liberally in evaluating novel treatment approaches to ARDS.
\end{abstract}

Copyright $\odot 2008$ S. Karger AG, Basel

\section{Introduction}

Acute lung injury (ALI), and its severest form, acute respiratory distress syndrome (ARDS) [1], are definitions of acute respiratory failure, caused by diffuse damage to the pulmonary parenchyma within hours to days by a variety of local or systemic insults [2]. Increased alveolar capillary membrane permeability, which is owing to widespread endothelial and epithelial disruption and/or diffuse inflammatory reaction in the pulmonary parenchyma, was recognized as the common end organ injury and a central feature in all forms of ALI/ARDS $[2,3]$. Arterial hypoxemia, which is refractory to treatment with supplemental oxygen, coupled with patchy infiltration on pulmonary roentgenogram, decreased dynamic pulmonary compliance and noncardiogenic edema are the characteristic clinical features [3].

Much is known about the different insults which can initiate and induce ALI/ARDS. In 1994 the AmericanEuropean Consensus Conference classified the insults as direct ('primary' or 'pulmonary') insults such as aspiration or smoke inhalation, which directly affect lung parenchyma, and indirect ('secondary' or 'extrapulmonary') insults such as sepsis and trauma, which result from an acute systemic inflammatory response [4]. In terms of risk, sepsis accounts for approximately $50 \%$ of all cases of ARDS. Pulmonary aspiration and trauma account for a further $25 \%$. Drug overdose, pancreatitis,

\section{KARGER}

Fax +41613061234 E-Mail karger@karger.ch www.karger.com
Hemei Wang, MD, PhD

Department of Anesthesiology, Johannes Gutenberg University Langenbeckstrasse 1

DE-55131 Mainz (Germany)

Tel. +496131 173 749, Fax +496131 176 649, E-Mail hemeiwang@gmx.de 
smoke inhalation, lung contusion and other factors constitute the remaining risk factors [3].

Despite the great strides made in understanding the pathogenesis of ALI/ARDS and in intensive care medicine, the mortality rates persist between 40 and 60\% [5]. To date, the main treatment approach to ARDS is still ventilatory and cardiovascular support based on the recognition of the clinical picture [3].

Animal experiments represent tremendously useful tools to explore the pathogenesis and to evaluate novel treatment approaches to ARDS, and have contributed significantly in the history of combating this life-threatening syndrome. They have provided invaluable help in piecing together the complex syndrome of ALI/ARDS [3]. Currently, large animal models of ALI (such as in pigs, dogs and sheep), induced by surfactant washout [lavage (LAV) model], oleic acid intravenous injection (OAI model) or endotoxin [lipopolysaccaride (LPS)] injection (LPS model), are intensively used in studies requiring invasive and exhaustive physiological monitoring with multiple blood sampling. Among these models, there exists an ongoing controversy regarding the underlying pathophysiology [6]. One view is supported by CT studies, which argues that, based on the observation in the LAV animal model, the pathophysiology in ARDS is mainly due to alveolar collapse and recruitment. The other view is based on studies with a parenchymal marker technique, stating that the pathophysiology in ARDS is persistent flooding of small airways and alveoli. To address the true scenario of this issue, it is necessary to have good knowledge of the pathology and histopathology of these animal models. This review intends to focus on the pathological characteristics from studies in porcine, dog or sheep models of ALI induced by LAV, OA or LPS. In the pathogenesis section we also report on data from species other than pigs, dogs and sheep because results from these 3 big animals were rather limited in this regard.

\section{Animal Modeling of ALI}

\section{LAV Model}

Protocols to induce lung injury by washout of the surfactant vary much between different studies. Adult pigs, dogs and sheep, of either sex, weighing 20-40 kg, are commonly used to establish this model [7-12]. Based on the purpose of the study, younger (even newborn) $[13,14]$ or older animals $[15,16]$ are also studied. Warmed normal saline $\left(37-39^{\circ} \mathrm{C}\right)$ is usually taken as the lavage fluid. Sometimes low concentrations of detergent, such as 0.2 or $0.5 \%$ of Tween 80 , are added to further inactivate the surfactant $[11,17]$. With the animal in the supine position, the bilateral lungs are lavaged repeatedly with an aliquot of $10-30 \mathrm{ml} / \mathrm{kg}$ of fluid per lavage cycle until the targeted lung injury level is achieved $[8,12,13,16,18]$. Larger volumes of lavage fluid, such as a volume of forced vital capacity [19], or a volume which is determined by instilling the solution from a height of $50 \mathrm{~cm}$ until a meniscus is seen in the endotracheal tube [20], are sometimes applied. In order to acquire a uniform degree of injury in the whole lung, some researchers $[11,18]$ shift the animals from the supine to the prone position or vice versa between the lavages. The criteria for lung injury are usually set as the $\mathrm{PaO}_{2}<100 \mathrm{~mm} \mathrm{Hg}$ at a $\mathrm{FIO}_{2}$ of 1.0 [14, $16,21,22]$. In some cases the extent of the lung injury is rather severe, with a $\mathrm{PaO}_{2}<40-60 \mathrm{~mm} \mathrm{Hg}[23,24]$, or just moderate with a $\mathrm{PaO}_{2}<300 \mathrm{~mm} \mathrm{Hg}[11,20]$. In very rare cases, in order to provide an intraindividual comparison, lung injury is produced only in a unilateral lung $[9,25]$.

\section{OAI Model}

The OAI model is usually performed by infusion of OA into the central vein or the right atrium through a femoral venous catheter or a pulmonary arterial catheter, respectively. The widely adopted dose of $\mathrm{OA}$ falls in the range of $0.06-0.15 \mathrm{ml} / \mathrm{kg}$, which is mixed thoroughly with $15-20 \mathrm{ml}$ of normal saline solution and injected slowly within 20-30 min [6, 26-29], targeting a $\mathrm{PaO}_{2} /$ $\mathrm{FIO}_{2}$ ratio of $80-120 \mathrm{~mm} \mathrm{Hg}$. Sometimes a dose as small as $0.01 \mathrm{ml} / \mathrm{kg}$ [30] is used to produce a very slight lung injury or a dose as high as $0.3 \mathrm{ml} / \mathrm{kg}$ [31] is applied to achieve a quite severe lung injury. Apart from the normal saline, pure or high concentration of ethanol $[32,33]$ or freshly drawn arterial blood [34-36] has been used as the dilution liquid for OA. The OA is administered continuously by a motor syringe or injected intermittently with some seconds of interruption to make sure the pulmonary pressure is not increased too high. To produce a uniform injury, sometimes the total dose of $\mathrm{OA}$ is partitioned into 3-4 equal aliquot portions [37, 38]. Every aliquot portion of the total dose is sequentially injected in the supine, right lateral, prone and left lateral position, respectively, with a few minutes of maintaining for each position before rotation to the next one.

\section{LPS Model}

LPS used to induce ARDS in pigs, dogs and sheep is usually extracted from Escherichia coli and consists of several serotypes including O111:B4 [39], O55:B5 [40], O26:B6 [34] and 0127:B8 [41]. Other sources of endotox- 
in, such as Salmonella enteritidis [42], are also used occasionally. In pigs and sheep, a dosage of $1-100 \mu \mathrm{g} / \mathrm{kg}$ of LPS is diluted in normal saline and infused intravenously over a half hour to several hours [39-41, 43-47]. In dogs, due to their tolerance to endotoxin, extremely high doses of endotoxin $(>1 \mathrm{mg} / \mathrm{kg})$ are routinely needed to induce this model $[48,49]$. The development of a stable lung injury by these dosages of LPS infusion usually takes several hours.

\section{The Pathogenesis of the LAV, OAI and LPS Animal Models of ALI}

\section{LAV Model}

Although there is no study yet which precisely addressed the pathogenesis of lavage-induced lung injury, depletion of lung alveolar surfactant (LAS) is believed to be responsible for the disorder of the lung gas exchange. Originally LAS is known to decrease the surface tension in alveolar spaces to a degree that facilitates adequate ventilation of the complete lung tissue [50]. LAS washout causes an increase in alveolar surface tension and results in large areas of atelectasis and decreased lung compliance, all of which brings about the abrupt decrease in $\mathrm{PaO}_{2}$ after lung lavages [51]. Furthermore, surfactant deficiency may promote the formation of pulmonary edema [50].

In addition to its surface activity, LAS has been demonstrated to enhance local pulmonary defense mechanisms and to modulate the immune response in the alveolar milieu [52]. Probably the most important surfactant component related to the pathogenesis of ARDS is surfactant protein-A, which has been suggested to play a role in protecting the lung from an overly exuberant inflammatory response by inhibiting neutrophil [polymorphonuclear leukocyte (PMN)] respiratory burst and having an antioxidant effect on alveolar macrophages [52]. On the one hand, abnormalities of LAS have been described in patients with ARDS and animals with ARDSlike injuries [50]. On the other hand, the hallmark of most forms of ALI is the accumulation of PMNs and dysregulation of their activation [1]. There could be a cause-effect link between deficiency or abnormality of LAS and the accumulation and dysregulated activation of PMNs. Recently Vangerow et al. [53] demonstrated on a rat lavage model that PMN accumulation in the alveoli showed a time-dependent increase after lavage, which may add some insights into that topic.

Pathology of Animal Models of Acute Lung Injury

\section{OAI Model}

Although the precise mechanisms by which OA induces lung edema and lung injury have not been elucidated yet, it was suggested that unsaturation of OA and its direct binding to biological membranes at very low concentrations is a possible mechanism [54]. Recently Vadasz et al. [55] found that $\mathrm{OA}$ at a concentration of 100 $\mu \mathrm{M}$ could bind, most likely covalently, with sodium channel and $\mathrm{Na}^{+}-\mathrm{K}^{+}$ATPase in epithelial cells, thus impairing the 2 essential transepithelial active sodium transport mechanisms of the lung. They [55] also found that a low concentration of OA $(25 \mu \mathrm{M})$ could increase the permeability of endothelial cells of isolated, ventilated and perfused rabbit lungs. Thus, OA could both promote alveolar and/or interstitial flooding by increasing the endothelial permeability and prevent fluid clearance by blocking active sodium transport. Both factors contribute to the development of ARDS.

There is a controversy over the role of cytokines in the pathogenesis of OA-induced lung injury. Most studies demonstrated increased levels of tumor necrosis factor $\alpha$ (TNF- $\alpha$ ) or interleukin 8 (IL-8) in lung tissue or serum/ plasma or bronchoalveolar lavage fluid after intravenous injection of OA in rats, mice, rabbits or dogs [56-60]. Suppression of TNF- $\alpha$ or IL- 8 by a variety of agents [5658] was accompanied by the amelioration of OA-induced lung injury. However, Rosenthal et al. [61] did not detect any increase in TNF- $\alpha$ in the pig arterial or mixed venous blood samples during the observation period from 60 to 165 min after OA injection.

Although there is considerable evidence for the accumulation of PMN in the lungs of different species after OA-induced injury [56, 62-64], the contribution of PMN to the pathogenesis of $\mathrm{OA}$-induced lung injury remains unclear. Eiermann et al. [62] demonstrated that depletion of rat PMN by anti-PMN serum significantly suppressed the increase in permeability induced by OA. Ito et al. [56] also found that depletion of rat peripheral blood PMNs could significantly increase $\mathrm{PaO}_{2} / \mathrm{FIO}_{2}$, attenuate the lung lesions including interstitial and intra-alveolar inflammatory cell influx, edema and hemorrhage ( $4 \mathrm{~h}$ after $\mathrm{OA})$, and reduce the increase in lung vascular permeability assessed by Evans blue dye measurement. Moriuchi et al. [65] showed that in vitro OA can directly activate PMNs from guinea pigs to release superoxide. Reactive oxygen species scavenger, N-acetyl-L-cysteine, significantly attenuated the increase in vascular permeability in the trachea. The authors inferred that PMNs may be involved in the pathogenesis of OA-induced lung injury. However, no beneficial effects of PMN depletion prior to

Eur Surg Res 2008;40:305-316 
OA administration were observed in other species models, such as sheep [66] and dogs [67].

A possible contribution of decreased ATP levels in the lung cells to the increased pulmonary vascular permeability after OA infusion was inferred by a recent study [68]. The authors found that phosphoenolpyruvate, one of the ATP precursors, could attenuate dose-dependently OA-induced decrease in the arterial partial pressure of oxygen as well as the increase in vascular permeability in the proximal and distal bronchi.

Other factors, such as reactive oxygen species, surfactant inactivation and eicosanoid (especially thromboxane), also play a role in the pathogenesis of OA-induced lung injury [54]. Acute fibrin deposition may not be harmful in the acute phase, and it may actually be beneficial in limiting alveolar flooding and hemorrhage [54]. More recently, Guimaraes et al. [69] demonstrated that endogenous endothelins, acting via endothelin receptor $B$ receptor-dependent mechanisms, play a major role in the mouse model of OA-induced lung injury by promoting infiltration of circulating PMNs and enhancement of pulmonary microvascular plasma extravasation.

\section{LPS Model}

As sepsis is still the most prevalent cause of ALI and ARDS in patients, the LPS model was widely studied to address the pathogenesis. It was believed that LPS may injure the lung by both a direct effect on the endothelium and its ability to trigger the release of a wide range of host-derived mediators of inflammation, including inflammatory cells and humoral factors [70-73]. As a proinflammatory molecule, LPS directly activates the endothelial cells by upregulating cytokines, adhesion molecules and tissue factors [72]. In addition, LPS can induce endothelial cell apoptosis [72]. In the LPS-induced secondary pathophysiological changes, activated neutrophils appear to play a central role [74], with other inflammatory cells (alveolar macrophages, lymphocytes and platelets) and a large number of humoral mediators such as activated complement, metabolites of arachidonic acid, reactive oxygen/nitrogen species, proteolytic enzymes, diverse cytokines and chemokines (e.g. TNF- $\alpha$, IL-1 $\beta$, IL-6 and IL-8) and adhesion molecules (e.g. intercellular adhesion molecule-1), etc., being involved [70, 71, 73]. LPS appears to initiate these secondary processes by interacting with a receptor complex on alveolar macrophages, neutrophils and other cells. LPS first forms a complex with a plasma glycoprotein, LPS-binding protein (LBP), which greatly enhances the interaction of LPS with its receptor CD14. At higher concentrations, LPS ac- tivates cells in the absence of LBP and CD14, probably through a different low-affinity signaling LPS receptor, L-selectin [75]. The binding of LPS-LBP complex with CD14 then activates the Toll-like receptor- 4 (with the assistance of a small secreted glycoprotein, MD-2) and causes the sequential activation of multiple signaling pathways and transcription factors, resulting in gene transcription. Consequently an orchestrated production of both pro- and anti-inflammatory mediators occurs [76].

In the last years, the relevance of platelets in numerous inflammatory processes other than hemostasis, such as sepsis and ischemia-reperfusion injury, has been recognized [77]. More recently in an elegant combination of in vivo and in vitro experiments, Zarbock et al. [78] revealed a critical role for platelets in the recruitment of PMN to the lung. The authors identified that platelets interact with PMNs through P-selectin, resulting in mutual cell activation and release of thromboxane $\mathrm{A}_{2}$ from their aggregates. Thromboxane $\mathrm{A}_{2}$ activates endothelial thromboxane $\mathrm{A}_{2}$ receptors and induces de novo expression of ICAM-1, triggering firm PMN adherence to endothelium via $\beta_{2}$-integrins [77, 78].

Jeyaseelan et al. [79] used microarrays to gain a global view of the transcriptional responses of the lung to LPS in a mouse model of ALI. They found that a total of 71 inflammation-associated genes were upregulated, most of which peaked $2 \mathrm{~h}$ after LPS treatment. In the meantime, they identified a role for LPS-induced CXC chemokine in the induction of ALI. Recently, a widely studied transcription factor and also growth factor, the high-mobility group box 1, was found to act as a cytokine mediator and to play a major role in the pathogenesis of endotoxin-induced ALI [80].

The cellular and humoral mediators mentioned above interact by forming a complicated network and triggering an amplified cascade of events, which culminate in cellular and tissue injury.

It is worthwhile to be noted that Siore et al. [81] recently reported that endotoxin-induced ALI requires interaction with the liver. They found that the direct effects of endotoxemia on the lungs were just vasoconstriction and leukocyte sequestration, with no lung injury observed. However, once both the liver and the lung were included in the blood-perfused circuit, endotoxin caused an intense activation of the inflammatory response and oxidative injury in the lung, which resulted in pulmonary edema and hypoxemia, i.e. ALI. 


\section{Pathological Findings on Pig, Dog and Sheep Models of ALI}

\section{LAV Model}

Kuckelt et al. [51] provided a relatively detailed morphological description of a pig LAV model. They induced the lung injury in LEWE-mini-pigs by repeated pulmonary lavages with normal saline until the animal died. On gross examination all the lobes were collapsed, airless, stiff and heavy. No hemorrhage was observed on the visceral pleura or in the lung tissue. The light microscopic picture of the lungs showed overdistended and atelectatic changes in different neighboring regions. Perivascular and peribronchial edema formation was prominent in all animals (fig. 1a). The blood vessels were normal, but the alveolocapillary membrane appeared thickened and deformed by several vacuoles (fig. 1b). The lymphatics seemed to be dilated. Electron microscopic examination demonstrated that the alveolocapillary membrane was severely destructed with all compartments (alveolar epithelial cells, basement membrane and endothelial cells) being affected (fig. 2). The alveolar type I cells appeared necrotic and desquamated. The cytoplasm of the pulmonary capillary endothelial cells also showed desquamation. The basement membrane and interstitial space became spread. Alveolar type II cells remained relatively intact, although the lamellar bodies seemed to be changed in quality and quantity.

Huber et al. [82] observed dilated capillaries and perivascular edema immediately after lavage (within $20 \mathrm{~min}$ ) in a dog preparation (5 times of repeated lavages with an aliquot of $100 \mathrm{ml}$ normal saline per cycle). There was no intra-alveolar hemorrhage or cellular necrosis. At $20 \mathrm{~min}$ after lavage electron microscopic examination showed increased vesiculation of capillary walls and swollen lamellated bodies within alveolar cells. These acute morphological changes appeared to be reversible in this model.

\section{OAI Model}

There were quite a few studies $[63,83-86]$ which described the OAI model in different species in detail. Ashbaugh and Uzawa [83] were the first ones who established this model in spontaneously breathing dogs. They found that, at a dose of $0.075 \mathrm{ml} / \mathrm{kg}$, free fatty acid (with a fraction of OA of 76.8\%) induced an irregular diffuse lesion in the lung within $5 \mathrm{~h}$ after injection, with normal-appearing lung interspersed in between hemorrhagic zones. On microscopic examination, arterioles were often filled with erythrocytes, many of which were partly or totally

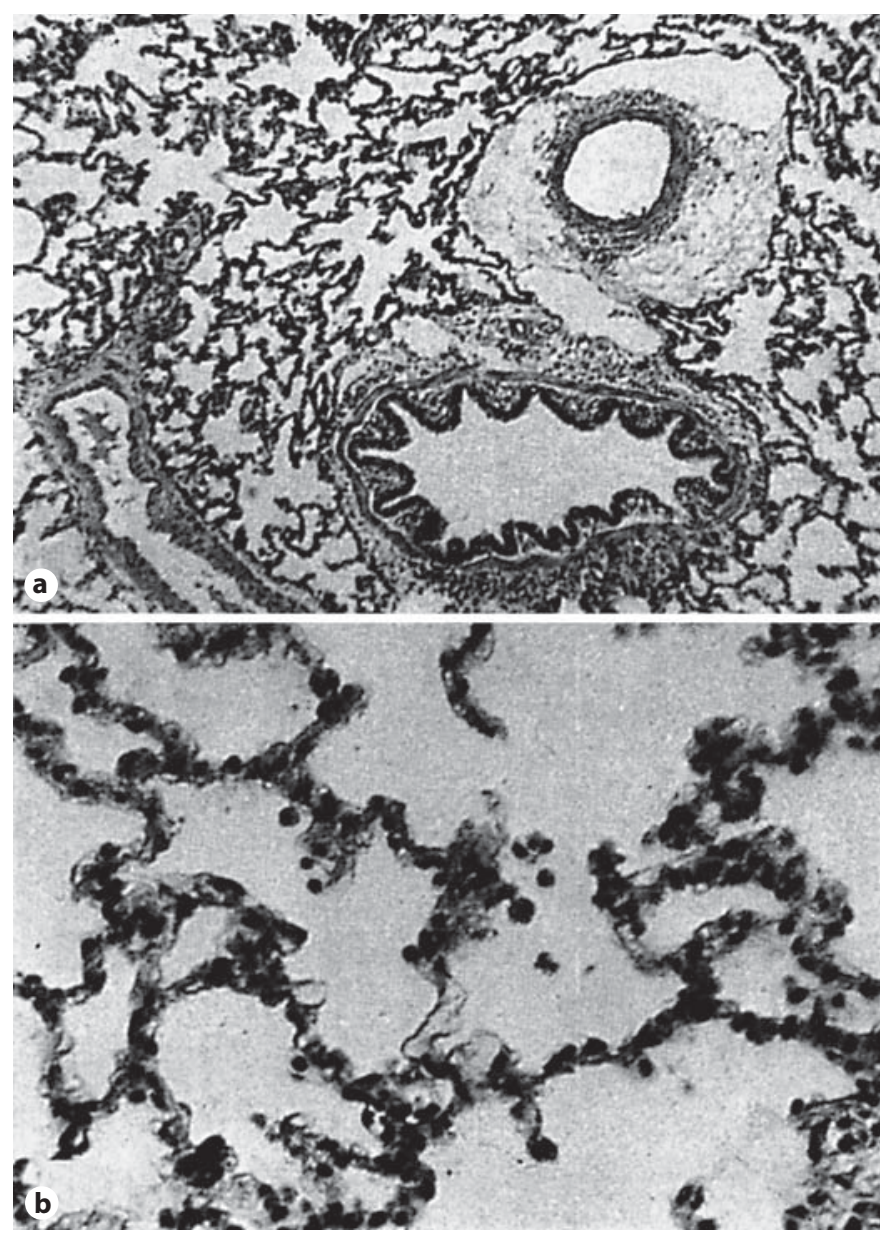

Fig. 1. Typical light microscopic findings in pig lungs after repeated pulmonary lavage. Most prominent lesions are perivascular and peribronchial edema. The lymphatics appear dilated. The alveoli seem to be reduced in their volume (a). At higher magnification (b) this picture is characterized by intraseptal vacuoles and desquamated epithelial cells. HE. Original magnification $\times 200(\mathbf{a}) ; \times 500$ (b). (Reprinted from Kuckelt et al. [51] with permission from Elsevier; fig. 7.)

hemolyzed. Interstitial edema, intra-alveolar edema and hemorrhage, and vascular congestion were commonly observed. Hyaline membranes and thrombi in smaller vessels were seen occasionally. Alveolar atelectasis varied from minimal to almost complete.

Derks and Jakobovitz-Derks [85] made a detailed description of the time course of pulmonary morphological changes after $\mathrm{OA}$ administration $(0.045$ or $0.09 \mathrm{~g} / \mathrm{kg})$ in a canine preparation. Six to twelve hours after OA injection the lungs showed alveolar flooding, capillary congestion, hemorrhage and septal necrosis (fig. 3). Fibrin 
deposition could be found on the alveolar surface. Thirty-six hours later these histopathologic changes became ameliorated. PMN and macrophage infiltration were found only a few hours after the initiation of OA injection. By 1 week, most of the acute lesions (except for some moderate edema) had disappeared, and type II cell proliferation and mononuclear cell infiltration became the most prominent lesions. Over 1-4 weeks, fibrosis and macrophage infiltration became progressively more com-

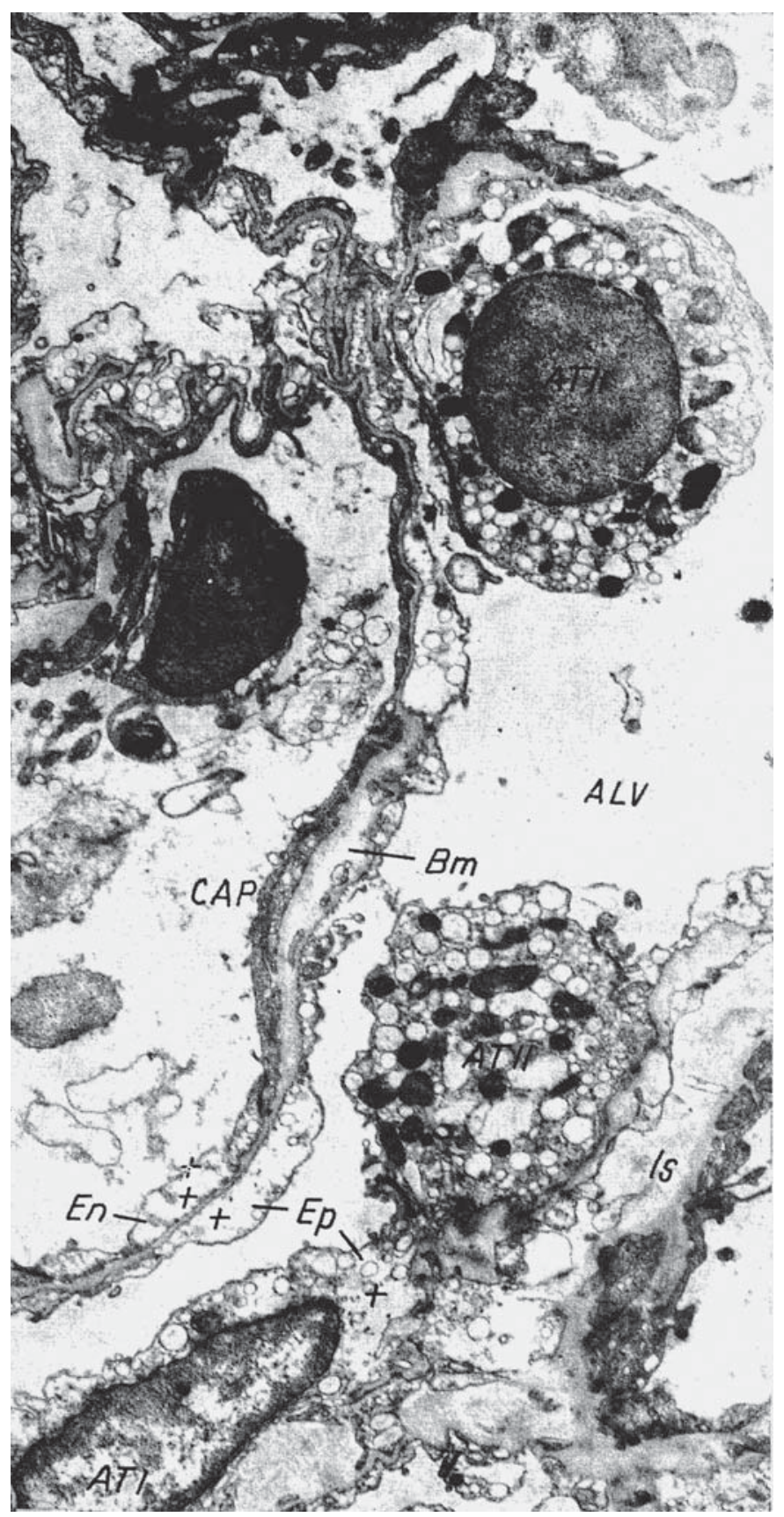

mon. The fibrotic changes were more pronounced in the lungs of the dogs which received a weekly administration of $0.09 \mathrm{~g} / \mathrm{kg}$ of pure OA over a period of $1-3$ months. In fibrotic regions, the alveoli were shrunken and the septa were thickened and infiltrated by fibroblasts, macrophages, lymphocytes and mast cells. The number of alveolar capillaries was reduced. Electron microscopic examination showed that capillaries were obstructed initially by newly formed thrombi composed of fibrin, platelets and cell debris. Endothelial and type I alveolar cells were necrotic and separated from their basal membrane (fig. 4a). After a few hours, capillary obstruction had disappeared. By 1 week, the most prominent change was that of type II cell proliferation (fig. 4b), which persisted for the following several weeks.

Miyazawa et al. [86] performed a pathological study on dog lungs $2 \mathrm{~h}$ after injection of $0.09 \mathrm{ml} / \mathrm{kg}$ OA. On gross examination the lungs were edematous and 2-3 times heavier than their normal weight. The surfaces were affected by blotchy hemorrhage. The trachea and main bronchi were usually associated with moderate to large amounts of bloody froth. Histologically the lung demonstrated impressive perivascular cuffing. The alveoli were filled with edema fluid. The electron microscopic examination of the mildly to moderately damaged regions showed that the interstitial tissues were thickened with edema fluid, capillary lumina were occupied by PMNs, and alveolar spaces were filled with plasma exudate containing erythrocytes, strands of fibrin, macrophages and electron-dense material which resembled surfactant and lamellar bodies, while the capillary endothelium and alveolar epithelium were not markedly degenerated. The electron microscopic findings of severely damaged lesions showed that both endothelium and epithelium were degenerative.

Fig. 2. Representative electron microphotograph of pig lungs after repeated pulmonary lavage. Note the necrosis and desquamation of alveolar type I cells (+), desquamation of cytoplasm of the pulmonary capillary endothelial cells $(++)$ and the spreading of the basement membrane and interstitial space. In contrast to these severe damages of the alveolar-capillary membrane, the alveolar type II cells remain relatively intact, although the lamellar bodies appear to be changed in quality and quantity. Original magnification $\times 6,000$. (Reprinted from Kuckelt et al. [51] with permission from Elsevier; fig. 8.) ALV = Alveolar space; CAP = pulmonary capillary; $\mathrm{Bm}$ = basement membrane; En = cytoplasm of pulmonary capillary endothelial cell; Ep = cytoplasm of pulmonary epithelial (alveolar type I) cell; Is = interstitial space; AT I = alveolar type I cell; AT II = alveolar type II cell. 


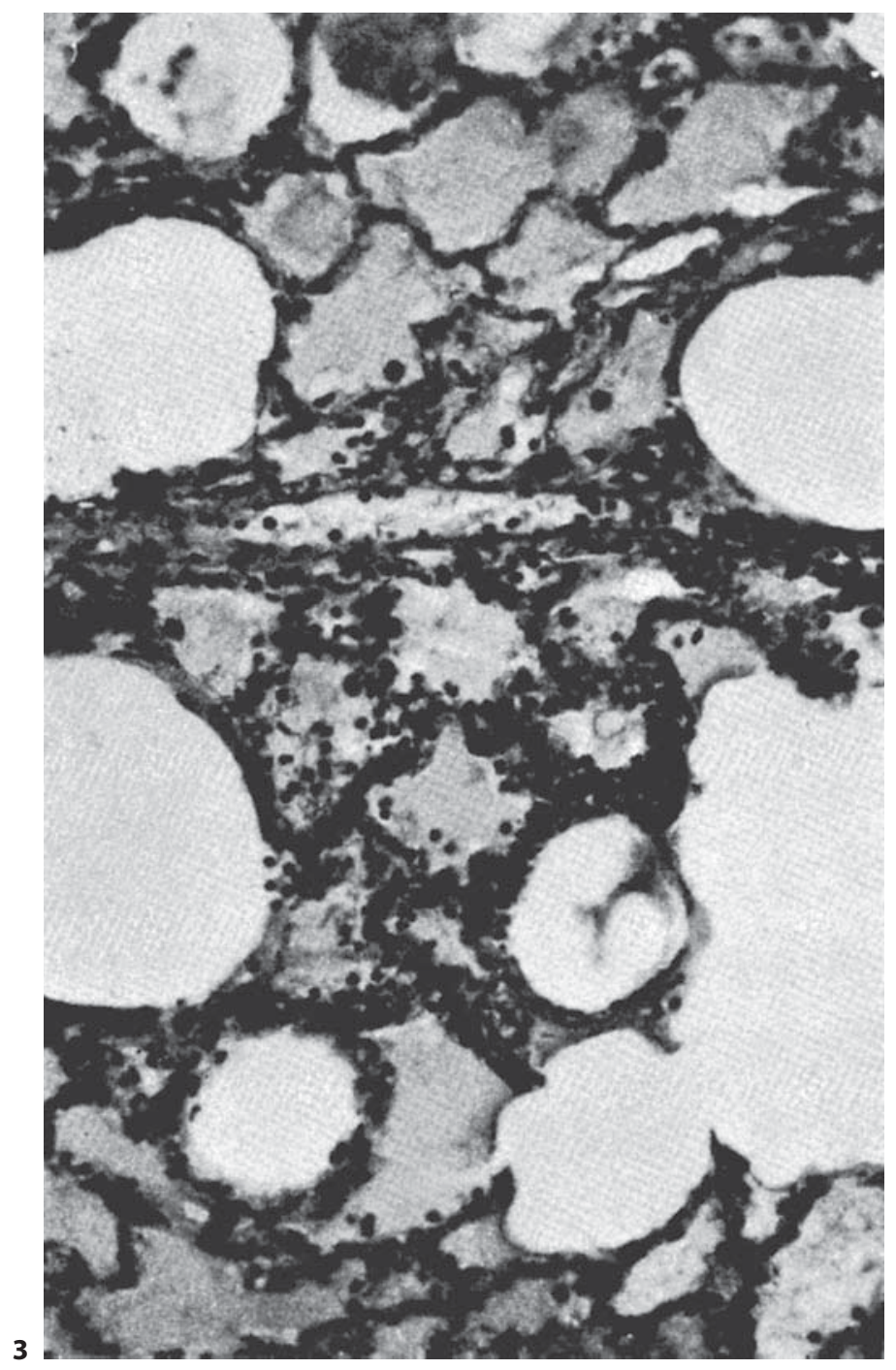

Fig. 3. Twelve hours after OA injection. Note septal necrosis which is infiltrated with PMNs. (Reprinted from Derks and JakobovitzDerks [85] with permission from the American Society for Investigative Pathology; fig. 4.)

Fig. 4. a Four hours after OA injection. Capillary endothelial cell containing myelin figures. Original magnification $\times 45,000$.
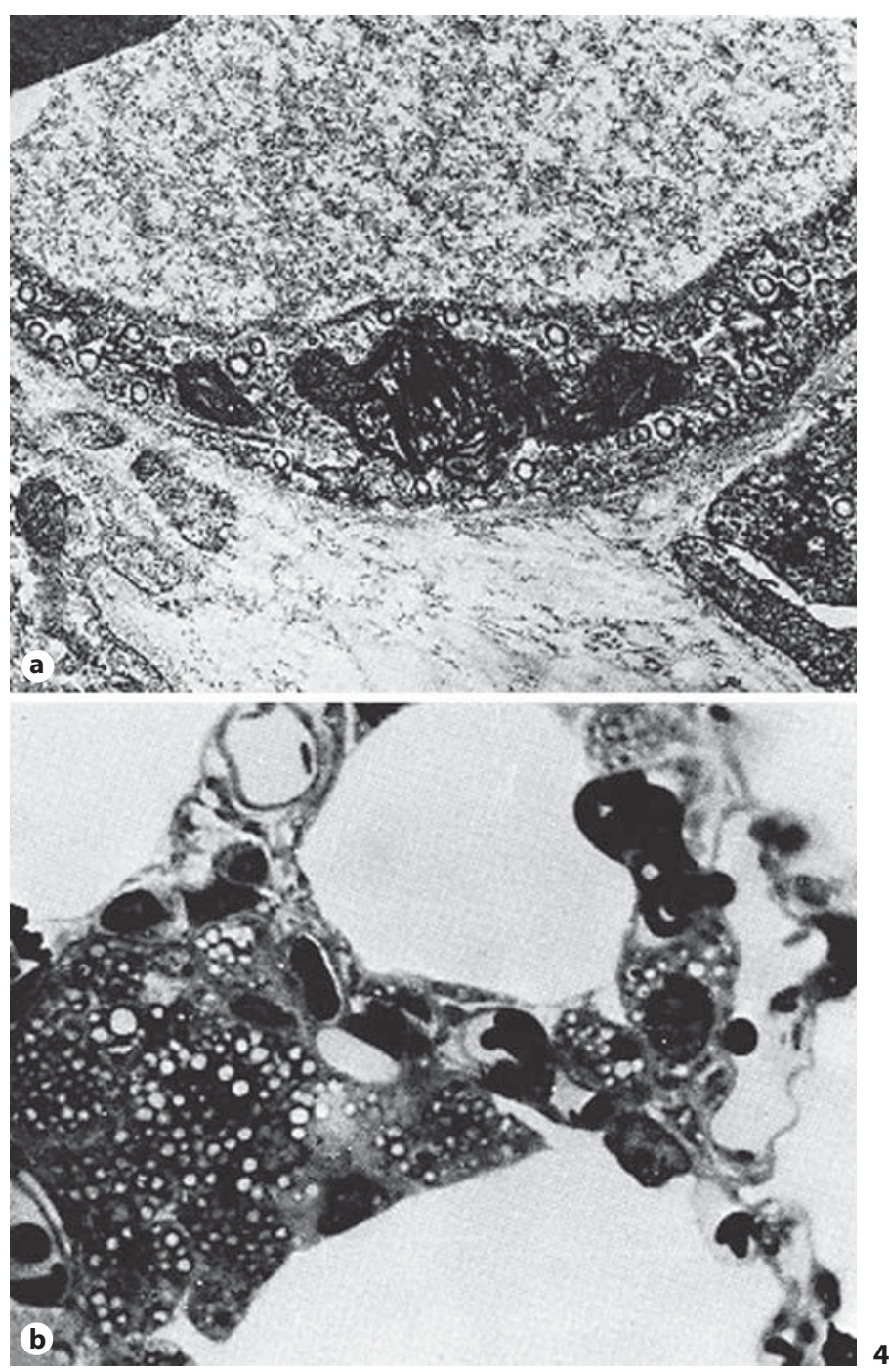

b One week after OA injection. Cluster of type II cells lying in an alveolus. Semithin section, Epon embedded. Original magnification $\times 1,000$. (Reprinted from Derks and Jakobovitz-Derks [85] with permission from the American Society for Investigative Pathology; fig. 6, 7.)

\section{LPS Model}

In contrast to the wide use of the pig, dog and sheep models of endotoxin-induced lung injury in the investigation of the pathomechanisms of ARDS and possible therapeutic interventions, the data on pathological descriptions of these models are quite limited. Most of the available data were from pigs and gathered $6 \mathrm{~h}$ after the initiation of LPS infusion (E. coli at $25-100 \mu \mathrm{g} / \mathrm{kg}$ over $1 \mathrm{~h})[39,43,46,87-90]$. Based on these studies, the most prominent alteration in the pig lungs was the sequestration of PMNs in the alveolar septa, spaces and interstitium $[39,43,46,87,89,90]$, accompanied by congestion, hemorrhage and interstitial edema (fig. 5a, b), all of which caused a marked thickening of alveolar walls. Another alteration was the dramatically increased number of alveolar macrophages $[39,87,89]$ which were markedly enlarged by the extensive presence of clear cytoplasmic vesicles [39]. LPS infusion was also associated with minor or 


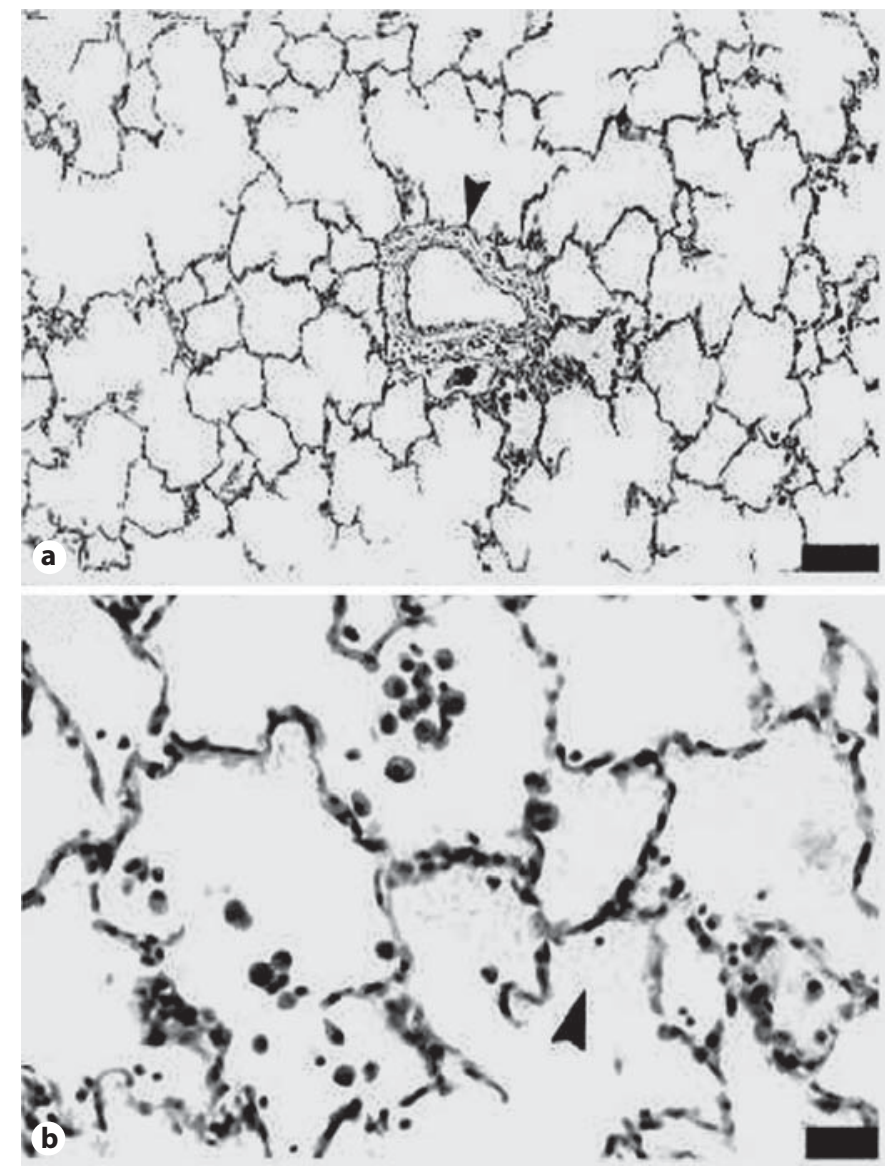

Fig. 5. Representative light microscopic pictures showing typical inflammatory response to LPS treatment. a Pig given $50 \mu \mathrm{g} / \mathrm{kg}$ LPS, scale bar $100 \mu \mathrm{m}$; arrowhead indicates edematous cuff surrounding a pulmonary vessel. b Pig given $25 \mu \mathrm{g} / \mathrm{kg}$ LPS, scale bar $25 \mu \mathrm{m}$; note leukocytic infiltration of the alveolar lumen; arrowhead indicates evidence of alveolar edema. (Reprinted from Picone et al. [89] with permission from Lippincott, Williams and Wilkins; fig. 1.)

severe atelectasis $[39,88]$, accumulation of detritus in the alveolar spaces [90], alveolar proteinaceous edema [43] and thrombosis [43]. There was a regional inhomogeneity throughout the specimens, with the pathological changes mentioned above interspersed with areas that appeared relatively normal [39].

At an ultrastructual level, Müller-Leisse et al. [91] found in a pig preparation that, after $17 \mathrm{~h}$ following LPS injection $(0.5 \mu \mathrm{g} / \mathrm{kg}$ E. coli LPS), type I cells showed a range of degenerative changes; the number of type II cells increased, and endothelial cells showed a spectrum of degenerative changes up to complete necrosis. Meyrick and Brigham [92] presented an ultrastructual time course de- scription in a sheep preparation. At 15 min after the start of LPS injection, granulocytes sequestered and marginated in the pulmonary microcirculation and began to show degranulation and fragmentation. Lymphocyte accumulation could also be seen in the pulmonary microcirculation. After $30 \mathrm{~min}$, the alveolar interstitium was often thickened, and isolated capillaries contained fibrin strands. Occasionally leukocytes were found in the process of migrating from the capillary lumen into the interstitium. By $60 \mathrm{~min}$, focal regions of endothelial cell damage were apparent, with increased electron density and increased numbers of pinocytic vesicles in the endothelial cytoplasm. Type I pneumocytes showed evidence of injury, and in some regions these cells had lifted from the basal lamina. These structural changes were sustained over at least a 4-hour period.

\section{Pathological Comparisons between the Three Animal Models and Human ALI/ARDS, and Their Clinical Relevance and Limitations}

Histologically, human ALI/ARDS can be subdivided into the exudative phase and the subsequent fibroproliferative phase [93]. The exudative phase is characterized by a diffuse neutrophilic alveolar infiltrate with hemorrhage, the accumulation of macrophages and proteinrich pulmonary edema $[93,94]$. Widespread atelectasis, injury of the alveolar-capillary and epithelial cells, and a procoagulant tendency featured by capillary thrombosis can be seen during this phase. Afterwards, the acute inflammation may resolve completely in some patients, but in others it progresses to the chronic fibroproliferative phase, during which chronic inflammation, fibrosis and neovascularization take place [93].

The direct comparison either between the 3 animal models or between the models and human ALI/ARDS is difficult because the pathological features are dependent on time, dose, species or even strains, and whether there are other interventions (such as a dedicated ventilation strategy) involved. In spite of this, a brief comparison of pathological characteristics between the 3 animal models and ALI/ARDS in humans is summarized in table 1.

The LAV model is primarily a surfactant depletion model which does not share all features of ALI/ARDS in humans. Therefore, it is probably suitable for studies which focus on the relevance of surfactant or the consequences of alveolar collapse, such as surfactant replacement treatment, the effect of different levels of airway pressures on alveolar recruitment, the description of cy- 
Table 1. Comparison of pathological characteristics between the 3 animal models and human ALI/ARDS

\begin{tabular}{|c|c|c|c|c|}
\hline Pathological characteristics & $\begin{array}{l}\text { Human } \\
\text { ALI/ARDS }\end{array}$ & $\begin{array}{l}\text { Animal } \\
\text { LAV model }\end{array}$ & $\begin{array}{l}\text { Animal } \\
\text { OAI model }\end{array}$ & $\begin{array}{l}\text { Animal } \\
\text { LPS model }\end{array}$ \\
\hline ARDS category & $\begin{array}{l}\text { pulmonary/ } \\
\text { extrapulmonary }\end{array}$ & pulmonary & extrapulmonary & extrapulmonary \\
\hline \multicolumn{5}{|l|}{ Exudative phase } \\
\hline Oxygenation & $\downarrow \downarrow \downarrow$ & $\downarrow \downarrow \downarrow$ & $\downarrow \downarrow \downarrow$ & $\downarrow \downarrow \downarrow$ \\
\hline Compliance & $\downarrow \downarrow \downarrow$ & $\downarrow \downarrow \downarrow$ & $\downarrow \downarrow \downarrow$ & $\downarrow \downarrow \downarrow$ \\
\hline Atelectasis & +++ & +++ & ++ & ++ \\
\hline Neutrophil infiltrate & +++ & + & +++ & +++ \\
\hline Macrophage infiltrate & ++ & \pm & ++ & ++ \\
\hline Alveolar proteinaceous edema & +++ & \pm & +++ & +++ \\
\hline Perivascular/peribronchial edema & +++ & +++ & +++ & +++ \\
\hline Endothelial cell necrosis & +++ & + & +++ & +++ \\
\hline Epithelial cell necrosis & +++ & + & +++ & +++ \\
\hline Endothelial cell apoptosis & $?$ & $?$ & $?$ & $?$ \\
\hline Epithelial cell apoptosis & $++[95]$ & $?$ & $++[96]$ & $?$ \\
\hline Congestion & ++ & + & +++ & +++ \\
\hline Alveolar hemorrhage & ++ & \pm & +++ & +++ \\
\hline Intravascular coagulation & + & $?$ & + & + \\
\hline Extravascular coagulation & ++ & $?$ & ++ & $?$ \\
\hline \multicolumn{5}{|l|}{ Fibroproliferative phase } \\
\hline Type II cell proliferation & +++ & $?$ & +++ & $?$ \\
\hline Mononuclear cell infiltrate & +++ & $?$ & +++ & $?$ \\
\hline Resolution of edema & +++ & $?$ & +++ & $?$ \\
\hline Fibroblast proliferation & ++ & $?$ & + & $?$ \\
\hline Fibrosis & ++ & $?$ & + & $?$ \\
\hline
\end{tabular}

$?=$ No available data for comparison; $\pm=$ no or little changes

clical recruitment and derecruitment, etc. It is obvious that the LAV model is unsuitable for investigating the pathogenesis of ALI/ARDS.

The OAI model well mimics the pathological features of ARDS mentioned above despite the different etiology from human ARDS [54]. Thus, the OAI model has been used extensively to study the consequence of lung injury and to evaluate potential new treatment strategies. However, because of its different etiology, the results from the OAI model should be cautiously extrapolated to human ARDS.

The LPS model may promise the most direct clinical relevance considering gram-negative sepsis being the clinical setting in which ALI is most common [70]. It is reasonable to use the LPS model to investigate the pathogenesis of ALI/ARDS and to evaluate the potential new treatment strategies. Unfortunately, it is unclear whether in the LPS models induced in pigs, dogs and sheep there exist similar fibroproliferative changes as in human ALI/ ARDS.

\section{Conclusion}

This review focuses on the pathological aspects of 3 widely applied pig, dog and sheep models of ALI, i.e. the LAV, OAI and LPS models. Although quite a lot of work has been done to describe the pathological pictures of these 3 models, a state-of-the-art description, which may provide data on spatial and temporal heterogeneity of the lung tissue, has not been achieved yet. The complete pathway of the pathogenesis in these models remains to be thoroughly clarified. We believe that a good morphological description on these models, both spatially and temporally, will help us gain a better understanding of the real pathophysiological picture and therefore apply these models more accurately and liberally in evaluating different novel treatment approaches to ARDS.

\section{Acknowledgment}

This review was partially funded by the German Research Foundation grant no. DFG-Ma 2398/3. 


\section{References}

$\nabla_{1}$ Lee W, Downey G: Neutrophil activation and acute lung injury. Curr Opin Crit Care 2001;7:1-7.

$\checkmark 2$ Luh S, Chiang C: Acute lung injury/acute respiratory distress syndrome (ALI/ARDS): the mechanism, present strategies and future perspectives of therapies. J Zhejiang Univ Sci B 2007;8:60-69.

$\checkmark 3$ Windsor AC, Mullen PG, Fowler AA: Acute lung injury: what have we learned from animal models? Am J Med Sci 1993;306:111-116.

-4 Bernard GR, Artigas A, Brigham KL, Carlet J, Falke K, Hudson L, Lamy M, Legall J, Morris A, Spragg R: The American-European consensus conference on ARDS: definitions, mechanisms, relevant outcomes, and clinical coordination. Am J Respir Crit Care Med 1994; 149:818-824.

$\checkmark 5$ Rocco PR, Zin WA: Pulmonary and extrapulmonary acute respiratory distress syndrome: are they different? Curr Opin Crit Care 2005;11:10-17.

6 Karmrodt J, Bletz C, Yuan S, David M, Heussel CP, Markstaller K: Quantification of atelectatic lung volumes in two different porcine models of ARDS. Br J Anaesth 2006;97:883895.

7 Odenstedt H, Aneman A, Karason S, Stenqvist O, Lundin S: Acute hemodynamic changes during lung recruitment in lavage and endotoxin-induced ALI. Intensive Care Med 2005;31:112-120.

$\checkmark 8$ Lethvall S, Lindgren S, Lundin S, Stenqvist O: Tracheal double-lumen ventilation attenuates hypercapnia and respiratory acidosis in lung injured pigs. Intensive Care Med 2004;30:686-692.

$\checkmark 9$ Blanch L, Van der Kloot TE, Youngblood AM, Murias G, Naveira A, Adams AB, Romero PV, Nahum A: Application of tracheal gas insufflation to acute unilateral lung injury in an experimental model. Am J Respir Crit Care Med 2001;164:642-647.

10 Kloot TE, Blanch L, Melynne Youngblood A, Weinert C, Adams AB, Marini JJ, Shapiro RS, Nahum A: Recruitment maneuvers in three experimental models of acute lung injury: effect on lung volume and gas exchange. Am J Respir Crit Care Med 2000;161:1485-1494.

-11 Musch G, Harris RS, Vidal Melo MF, O’Neill KR, Layfield JD, Winkler T, Venegas JG: Mechanism by which a sustained inflation can worsen oxygenation in acute lung injury. Anesthesiology 2004;100:323-330.

12 Kirmse M, Fujino Y, Hess D, Kacmarek RM: Positive end-expiratory pressure improves gas exchange and pulmonary mechanics during partial liquid ventilation. Am J Respir Crit Care Med 1998;158:1550-1556.

13 Fuchs JR, Kaviani A, Watson K, Thompson J, Wilson JM, Fauza DO: Intratracheal pulmonary ventilation improves gas exchange during laparoscopy in a pediatric lung injury model. J Pediatr Surg 2005;40:22-25.
14 Manaligod JM, Bendel-Stenzel EM, Meyers PA, Bing DR, Connett JE, Mammel MC: Variations in end-expiratory pressure during partial liquid ventilation: impact on gas exchange, lung compliance, and end-expiratory lung volume. Chest 2000;117:184-190.

15 Bellardine CL, Hoffman AM, Tsai L, Ingenito EP, Arold SP, Lutchen KR, Suki B: Comparison of variable and conventional ventilation in a sheep saline lavage lung injury model. Crit Care Med 2006;34:439-445.

${ }_{16}$ Zick G, Frerichs I, Schadler D, Schmitz G, Pulletz S, Cavus E, Wachtler F, Scholz J, Weiler N: Oxygenation effect of interventional lung assist in a lavage model of acute lung injury: a prospective experimental study. Crit Care 2006;10:R56.

-17 Kobayashi H, Tanaka N, Winkler M, Zapol WM: Combined effects of NO inhalation and intravenous PGF2 alpha on pulmonary circulation and gas exchange in an ovine ARDS model. Intensive Care Med 1996;22: 656-663.

18 Bellardine Black CL, Hoffman AM, Tsai LW, Ingenito EP, Suki B, Kaczka DW, Simon BA, Lutchen KR: Relationship between dynamic respiratory mechanics and disease heterogeneity in sheep lavage injury. Crit Care Med 2007;35:870-878.

$>19$ Dolan S, Derdak S, Solomon D, Farmer C, Johanningman J, Gelineau J, Smith RB: Tracheal gas insufflation combined with highfrequency oscillatory ventilation. Crit Care Med 1996;24:458-465.

20 Luecke T, Meinhardt JP, Herrmann P, Weiss A, Quintel M, Pelosi P: Oleic acid vs saline solution lung lavage-induced acute lung injury: effects on lung morphology, pressurevolume relationships, and response to positive end-expiratory pressure. Chest 2006; 130:392-401.

-21 Henzler D, Mahnken AH, Wildberger JE, Rossaint R, Gunther RW, Kuhlen R: Multislice spiral computed tomography to determine the effects of a recruitment maneuver in experimental lung injury. Eur Radiol 2006;16:1351-1359.

22 Greif WM, Forse RA: Cardiopulmonary effects of the laparoscopic pneumoperitoneum in a porcine model of adult respiratory distress syndrome. Am J Surg 1999;177:216-221.

23 Brederlau J, Muellenbach R, Kredel M, Kuestermann J, Anetseder M, Greim C, Roewer $\mathrm{N}$ : Combination of arteriovenous extracorporeal lung assist and high-frequency oscillatory ventilation in a porcine model of lavage-induced acute lung injury: a randomized controlled trial. J Trauma 2007;62: $336-346$.
-24 Kredel M, Muellenbach RM, Brock RW, Wilckens HH, Brederlau J, Roewer N, Wunder C: Liver dysfunction after lung recruitment manoeuvres during pressure-controlled ventilation in experimental acute respiratory distress. Crit Care 2007;11:R13.

25 Ye SQ, Simon BA, Maloney JP, ZambelliWeiner A, Gao L, Grant A, Easley RB, McVerry BJ, Tuder RM, Standiford T, Brower RG, Barnes KC, Garcia JG: Pre-B-cell colony-enhancing factor as a potential novel biomarker in acute lung injury. Am J Respir Crit Care Med 2005;171:361-370.

26 Claesson J, Lehtipalo S, Bergstrand U, Arnerlov C, Winso O: Negative mesenteric effects of lung recruitment maneuvers in oleic acid lung injury are transient and short lasting. Crit Care Med 2007;35:230-238.

$\checkmark 27$ Roch A, Michelet P, Lambert D, Delliaux S, Saby C, Perrin G, Ghez O, Bregeon F, Thomas P, Carpentier JP, Papazian L, Auffray JP: Accuracy of the double indicator method for measurement of extravascular lung water depends on the type of acute lung injury. Crit Care Med 2004;32:811-817.

28 Gust R, McCarthy TJ, Kozlowski J, Stephenson AH, Schuster DP: Response to inhaled nitric oxide in acute lung injury depends on distribution of pulmonary blood flow prior to its administration. Am J Respir Crit Care Med 1999;159:563-570.

29 Neumann P, Berglund JE, Mondejar EF, Magnusson A, Hedenstierna G: Effect of different pressure levels on the dynamics of lung collapse and recruitment in oleic-acidinduced lung injury. Am J Respir Crit Care Med 1998;158:1636-1643.

30 Zwissler B, Forst H, Ishii K, Messmer K: A new experimental model of ARDS and pulmonary hypertension in the dog. Res Exp Med (Berl) 1989;189:427-438.

31 Schweiger JW, Downs JB, Smith RA: Chest wall disruption with and without acute lung injury: effects of continuous positive airway pressure therapy on ventilation and perfusion relationships. Crit Care Med 2003;31: 2364-2370.

>32 Ludwigs U, Klingstedt C, Baehrendtz S, Wegenius $G$, Hedenstierna G: A functional and morphologic analysis of pressure-controlled inverse ratio ventilation in oleic acid-induced lung injury. Chest 1994;106:925-931.

33 Grotjohan HP, van der Heijde RM, Jansen JR, Wagenvoort CA, Versprille A: A stable model of respiratory distress by small injections of oleic acid in pigs. Intensive Care Med 1996;22:336-344.

34 Kirov MY, Kuzkov VV, Kuklin VN, Waerhaug K, Bjertnaes LJ: Extravascular lung water assessed by transpulmonary single thermodilution and postmortem gravimetry in sheep. Crit Care 2004;8:R451-R458. 
-35 Ragaller M, Bleyl J, Tscho U, Winkler T, Regner M, Rasche S, Koch T, Albrecht M: Effects of inhalation of perfluorocarbon aerosol on oxygenation and pulmonary function compared to PGI2 inhalation in a sheep model of oleic acid-induced lung injury. Intensive Care Med 2001;27:889-897.

- 36 Overbeck MC, Pranikoff T, Yadao CM, Hirschl RB: Efficacy of perfluorocarbon partial liquid ventilation in a large animal model of acute respiratory failure. Crit Care Med 1996;24:1208-1214.

- 37 Broccard AF, Shapiro RS, Schmitz LL, Ravenscraft SA, Marini JJ: Influence of prone position on the extent and distribution of lung injury in a high tidal volume oleic acid model of acute respiratory distress syndrome. Crit Care Med 1997;25:16-27.

- 38 Lee HJ, Im JG, Goo JM, Kim YI, Lee MW, Ryu HG, Bahk JH, Yoo CG: Acute lung injury: effects of prone positioning on cephalocaudal distribution of lung inflation - CT assessment in dogs. Radiology 2005;234: 151-161.

-39 Nieman GF, Gatto LA, Paskanik AM, Yang B, Fluck R, Picone A: Surfactant replacement in the treatment of sepsis-induced adult respiratory distress syndrome in pigs. Crit Care Med 1996;24:1025-1033.

-40 Albertini M, Clement MG, Lafortuna CL, Caniatti M, Magder S, Abdulmalek K, Hussain SN: Role of poly-(ADP-ribose) synthetase in lipopolysaccharide-induced vascular failure and acute lung injury in pigs. J Crit Care 2000;15:73-83.

41 Pacht ER, Kindt GC, Lykens MG: Increased antioxidant activity in bronchoalveolar lavage fluid after acute lung injury in anesthetized sheep. Crit Care Med 1992;20:14411447.

-42 Welsh C, Lien D, Worthen G, Weil J: Pentoxifylline decreases endotoxin-induced pulmonary neutrophil sequestration and extravascular protein accumulation in the dog. Am Rev Respir Dis 1988;138:1106-1114.

-43 Da J, Chen L, Hedenstierna G: Nitric oxide up-regulates the glucocorticoid receptor and blunts the inflammatory reaction in porcine endotoxin sepsis. Crit Care Med 2007;35:2632.

44 Maurenbrecher H, Lamy M, Deby-Dupont G, Frascarolo P, Hedenstierna G: An animal model of response and nonresponse to inhaled nitric oxide in endotoxin-induced lung injury. Chest 2001;120:573-581.

-45 Dahm PL, Blomquist S, De Robertis E, Jonson B, Myhre E, Svantesson C, Thorne J: Effects of NO inhalation on pulmonary leukocyte sequestration and blood volume in porcine endotoxaemia. Intensive Care Med 2000;26:336-343.

-46 Lutz C, Carney D, Finck C, Picone A, Gatto LA, Paskanik A, Langenback E, Nieman G: Aerosolized surfactant improves pulmonary function in endotoxin-induced lung injury. Am J Respir Crit Care Med 1998;158:840845 .
47 Modig J, Borg T: Biochemical markers in a porcine model of adult respiratory distress syndrome induced by endotoxemia. Resuscitation 1986;14:225-236.

48 Tabor DR, Kiel DP, Jacobs RF: Receptor-mediated ingestion responses by lung macrophages from a canine model of ARDS. J Leukoc Biol 1987;41:539-543.

49 Jacobs RF, Kiel DP, Balk RA: Alveolar macrophage function in a canine model of endotoxin-induced lung injury. Am Rev Respir Dis 1986;134:745-751.

50 Holm B, Matalon S: Role of pulmonary surfactant in the development and treatment of adult respiratory distress syndrome. Anesth Analg 1989;69:805-818.

51 Kuckelt W, Dauberschmidt R, Bender V, Hieronymi $\mathrm{U}$, Mrochen $\mathrm{H}$, Winsel $\mathrm{K}$, Meyer $\mathrm{M}$ : Experimental investigations in adult respiratory distress syndrome (ARDS): repeated pulmonary lavage in LEWE-mini-pigs. I. Pulmonary mechanics, gas exchange, and pulmonary hemodynamics. Exp Pathol 1981;20:88-104

52 Mallory G: Surfactant proteins: role in lung physiology and disease in early life. Paediatr Respir Rev 2001;2:151-158.

53 Vangerow B, Hafner D, Rueckoldt H, Marx G, Ott N, Leuwer M, Frerking I, Germann PG: Effects of $\mathrm{C} 1$ inhibitor and r-SP-C surfactant on oxygenation and histology in rats with lavage-induced acute lung injury. Intensive Care Med 2001;27:1526-1531.

54 Schuster DP: ARDS: clinical lessons from the oleic acid model of acute lung injury. Am J Respir Crit Care Med 1994;149:245-260.

55 Vadasz I, Morty RE, Kohstall MG, Olschewski A, Grimminger F, Seeger W, Ghofrani HA: Oleic acid inhibits alveolar fluid reabsorption: a role in acute respiratory distress syndrome? Am J Respir Crit Care Med 2005; 171:469-479.

56 Ito K, Mizutani A, Kira S, Mori M, Iwasaka $\mathrm{H}$, Noguchi T: Effect of Ulinastatin, a human urinary trypsin inhibitor, on the oleic acidinduced acute lung injury in rats via the inhibition of activated leukocytes. Injury 2005 ; 36:387-394

57 Chen J, Zhao J, Wang G: Preventive effects and mechanism of heme oxygenase-1 activation on acute respiratory distress syndrome in rats. Zhonghua Lao Dong Wei Sheng Zhi Ye Bing Za Zhi 2005;23:199-202.

58 Xu GL, Yao L, Rao SY, Gong ZN, Zhang SQ, Yu SQ: Attenuation of acute lung injury in mice by oxymatrine is associated with inhibition of phosphorylated p38 mitogen-activated protein kinase. J Ethnopharmacol 2005;98:177-183.

59 Nakazawa K, Yokoyama K, Yamakawa N Makita K: Effect of positive end-expiratory pressure on inflammatory response in oleic acid-induced lung injury and whole-lung lavage-induced lung injury. J Anesth 2007;21: $47-54$
60 Xie L, Liu Y, Zhao X, Chen L, Huang L, Hao F, Cao L: Effects of prone position ventilation on inflammatory factors in blood and bronchial alveolar lavage fluid of acute respiratory distress syndrome dogs caused by pulmonary and extrapulmonary insults. Zhonghua Yi Xue Za Zhi 2004;84:12001204.

61 Rosenthal C, Caronia C, Quinn C, Lugo N, Sagy M: A comparison among animal models of acute lung injury. Crit Care Med 1998; 26:912-916.

62 Eiermann G, Dickey B, Thrall R: Polymorphonuclear leukocyte participation in acute oleic-acid-induced lung injury. Am Rev Respir Dis 1983;128:845-850.

63 Schoene R, Robertson H, Thorning D, Springmeyer S, Hlastala M, Cheney F: Pathophysiological patterns of resolution from acute oleic acid injury in the dog. J Appl Physiol 1984;56:472-481.

64 Ball H, Cook J, Spicer K, Wise W, Halushka $P$ : Essential fatty acid-deficient rats are resistant to oleic acid-induced pulmonary injury. J Appl Physiol 1989;67:811-816.

65 Moriuchi H, Zaha M, Fukumoto T, Yuizono T: Activation of polymorphonuclear leukocytes in oleic acid-induced lung injury. Intensive Care Med 1998;24:709-715.

66 Julien M, Hoeffel J, Flick M: Oleic acid injury in sheep. J Appl Physiol 1986;60:433-440.

$\checkmark 67$ Hofman W, Ehrhart I: Permeability edema in dog lung depleted of blood components. J Appl Physiol 1984;57:147-153.

68 Golbidi S, Moriuchi H, Yang C, Irikura M, Irie $\mathrm{T}$, Hamasaki $\mathrm{N}$ : Preventive effect of phosphoenolpyruvate on hypoxemia induced by oleic acid in guinea pigs. Biol Pharm Bull 2003;26:336-340.

69 Guimaraes CL, Trentin PG, Rae GA: Endothelin $\mathrm{ET}_{\mathrm{B}}$ receptor-mediated mechanisms involved in oleic acid-induced acute lung injury in mice. Clin Sci (Lond) 2002;103(suppl 48):340S-344S

70 Brigham KL, Meyrick B: Endotoxin and lung injury. Am Rev Respir Dis 1986;133:913927.

71 Welbourn CR, Young Y: Endotoxin, septic shock and acute lung injury: neutrophils, macrophages and inflammatory mediators. Br J Surg 1992;79:998-1003.

72 Bannerman DD, Goldblum SE: Mechanisms of bacterial lipopolysaccharide-induced endothelial apoptosis. Am J Physiol Lung Cell Mol Physiol 2003;284:L899-L914.

73 Bhatia M, Moochhala S: Role of inflammatory mediators in the pathophysiology of acute respiratory distress syndrome. J Pathol 2004;202:145-156.

74 Abraham E: Neutrophils and acute lung injury. Crit Care Med 2003;31(suppl 4):S195S199.

75 Malhotra R, Bird M: L-selectin: a novel receptor for lipopolysaccharide and its potential role in bacterial sepsis. Bioessays 1997; 19:919-923. 
76 Monick M, Hunninghake G: Activation of second messenger pathways in alveolar macrophages by endotoxin. Eur Respir J 2002;20: 210-222.

77 Kuebler W: Selectins revisited: the emerging role of platelets in inflammatory lung disease. J Clin Invest 2006;116:3106-3108.

78 Zarbock A, Singbartl K, Ley K: Complete reversal of acid-induced acute lung injury by blocking of platelet-neutrophil aggregation. J Clin Invest 2006;116:3211-3219.

79 Jeyaseelan S, Chu H, Young S, Worthen G: Transcriptional profiling of lipopolysaccharide-induced acute lung injury. Infect Immun 2004;72:7247-7256.

$>80$ Wang H, Yang H, Tracey K: Extracellular role of HMGB1 in inflammation and sepsis. J Intern Med 2004;255:320-331.

-81 Siore AM, Parker RE, Stecenko AA, Cuppels C, McKean M, Christman BW, Cruz-Gervis R, Brigham KL: Endotoxin-induced acute lung injury requires interaction with the liver. Am J Physiol Lung Cell Mol Physiol 2005; 289:L769-L776.

$>2$ Huber G, Edmunds L, Finley T: Acute effect of saline lung washing on pulmonary mechanics and morphology. Surg Forum 1966; 17:113-114.
83 Ashbaugh D, Uzawa T: Respiratory and hemodynamic changes after injection of free fatty acids. J Surg Res 1968;8:417-423.

84 King E, Nakane P, Ashbaugh D: The canine oleic acid model of fibrin localization in fat embolism. Surgery 1971;69:782-787.

85 Derks C, Jakobovitz-Derks D: Embolic pneumopathy induced by oleic acid: a systematic morphologic study. Am J Pathol 1977;87: 143-158.

86 Miyazawa T, Nakagawa H, Hiramoto M, Arita K, Hiramoto T, Nishida O: Ultrastructural study on the alveolar-capillary injury with pulmonary edema induced by oleic acid in dogs. Hiroshima J Med Sci 1981;30:183190.

87 Lutz CJ, Picone A, Gatto LA, Paskanik A, Landas S, Nieman GF: Exogenous surfactant and positive end-expiratory pressure in the treatment of endotoxin-induced lung injury. Crit Care Med 1998;26:1379-1389.

88 Sood SL, Balaraman V, Finn KC, Wilkerson SY, Mundie TG, Easa D: Exogenous surfactant decreases oxygenation in Escherichia coli endotoxin-treated neonatal piglets. Pediatr Pulmonol 1996;22:376-386.

89 Picone A, Gatto LA, Nieman GF, Paskanik AM, Lutz C: Pulmonary surfactant function following endotoxin: effects of exogenous surfactant treatment. Shock 1996;5:304310.

90 Kemming G, Flondor M, Hanser A, Pallivathukal S, Holtmannspoetter M, Kneisel F, Reuter D, Kisch-Wedel H, Zwissler B: Effects of perfluorohexan vapor on gas exchange, respiratory mechanics, and lung histology in pigs with lung injury after endotoxin infusion. Anesthesiology 2005;103:585-594.
91 Müller-Leisse C, Klosterhalfen B, Hauptmann S, Simon H, Kashefi A, Andreopoulos D, Kirkpatrick C, Guenther R: Computed tomography and histologic results in the early stages of endotoxin-injured pig lungs as a model for adult respiratory distress syndrome. Invest Radiol 1993;28:39-45.

92 Meyrick B, Brigham K: Acute effects of $E$. coli endotoxin on the pulmonary microcirculation of anesthetized sheep: structure and function relationships. Lab Invest 1983; 48:458-470.

93 Wheeler A, Bernard G: Acute lung injury and the acute respiratory distress syndrome: a clinical review. Lancet 2007;369:15531564.

94 Ware L, Matthay M: The acute respiratory distress syndrome. N Engl J Med 2000;342: 1334-1349.

95 Matute-Bello G, Martin T: Science review: apoptosis in acute lung injury. Crit Care 2003; 7:355-358.

$\$ 96$ Mantell L, Kazzaz J, Xu J, Palaia T, Piedboeuf B, Hall S, Rhodes G, Niu G, Fein A, Horowitz S: Unscheduled apoptosis during acute inflammatory lung injury. Cell Death Differ 1997;4:600-607. 